\title{
Women and Smoking: The Effect of Gender on the Epidemiology, Health Effects, and Cessation of Smoking
}

\author{
Alicia M. Allen • Cheryl Oncken • Dorothy Hatsukami
}

Published online: 10 January 2014

(C) Springer International Publishing AG 2014

\begin{abstract}
Smoking is still the leading cause of premature morbidity and mortality. This paper examines new research on gender differences and the epidemiology of smoking, smoking-related morbidity and mortality, and factors that affect smoking cessation. The rate of decline in the prevalence of smoking has been slowing, especially among adolescent girls. New research suggests that, compared with men, women may be more susceptible to smoking-related morbidity and mortality. Gender-related barriers to smoking cessation include weight gain, sex hormones, and mood. Furthermore, the sensory aspects of smoking may have more of an effect on smoking treatment for women than for men. We discuss new studies that examine smoking-cessation interventions that may be particularly beneficial for women, including exercise (as an adjunct intervention), very low nicotine content cigarettes, and a variety of pharmacotherapy. Further research is needed to identify and target the gender-specific needs of smokers.
\end{abstract}

Keywords Smoking $\cdot$ Nicotine $\cdot$ Health Effects $\cdot$ Cessation · Sex Hormones · Women · Gender

\footnotetext{
A. M. Allen $(\bowtie)$

Department of Family Medicine and Community Health, Medical School, University of Minnesota, 717 Delaware Street SE, Room 422, Minneapolis, MN 55414, USA

e-mail: alle0299@umn.edu

C. Oncken

Department of Medicine and Obstetrics and Gynecology, University of Connecticut School of Medicine, 263 Farmington, Farmington, CT 06030, USA

e-mail: Oncken@nso2.uchc.edu

D. Hatsukami

Department of Psychiatry, Medical School, University of Minnesota, 717 Delaware Street SE, Room 256, Minneapolis, MN 55414, USA e-mail: hatsu001@umn.edu
}

\section{Introduction}

Smoking is a leading cause of preventable morbidity and mortality in the United States [1-3]. Fortunately, smoking cessation at any age can reduce excess risk of mortality, with quitting smoking before age 40 reducing excess risk of mortality by an estimated $90 \%[4 \bullet, 5]$. Although the prevalence of smoking is somewhat greater among men than women, women may have a higher risk of smoking-related morbidity and mortality, and face different barriers to smoking cessation that warrant intervention. The purpose of this review is to provide an update (since 2010) on research on women and smoking and, where appropriate, gender differences related to smoking behavior. We will review the epidemiology and health effects of smoking, and factors that may affect cessation. Although the literature on smoking and pregnancy is rapidly expanding, that topic will not be included because several recent reviews have been published $[6,7]$.

\section{Epidemiology of Smoking}

In 2011, approximately $19 \%$ of Americans reported current cigarette smoking [8]. More men than women smoke from when they are adolescents in middle school (4.0\% women vs. $4.5 \%$ men) to middle age (45-64 year olds; $18.5 \%$ women vs. $24.5 \%$ men) $[8,9]$. Conversely, among those aged 65 and older the prevalence of smoking is slightly higher for women (9.3\% women vs. $8.9 \%$ men) [8].

Although the prevalence of smoking among adolescents and adults has declined over the past ten years, the rate of decline is slowing $[8,9]$. These trends vary by gender and age, such that among adolescents the prevalence of smoking has declined less in females, whereas among adults a greater decline has been observed in women. For instance, from 2009 to 2010, the prevalence of smoking declined by 
$17.5 \%$ among middle-school females versus a $24.4 \%$ decline among middle-school males [9]. In adults from 2010 to 2011, smoking prevalence among men essentially remained stagnant, whereas a $5 \%$ reduction was observed among women [8]. These data indicate that the gender gap in smoking prevalence may be narrowing, and that additional efforts to reduce smoking prevalence among teenage girls and older women are warranted.

\section{Health Effects of Smoking}

The health effects of smoking are extensive and well documented [1-3]. Although the prevalence of smoking is declining, the relative risk of death for current and former smokers continues to rise $\left[10^{\bullet}\right]$. Each year in the United States 200,000 men and 180,000 women die as a result of smoking [11]. In a study of over 1.2 million women in the United Kingdom, Pirie et al. [4•] found that approximately $66 \%$ of deaths among smokers 50-70 years old were directly attributable to smoking, resulting, on average, in a loss of 10 years of life [4•]. Although obesity places smokers at an even greater risk of premature mortality, heavy smokers ( $>20$ cigarettes a day) have the greatest risk of middle-aged death, regardless of body mass index [12].

\section{Smoking and Cancer}

The effect of smoking on the risk of specific cancers may be stronger for women than men. Compared with their non-smoker peers, women smokers are at significantly greater risk of advanced colorectal neoplasia after as little as 10 pack-years of smoking, whereas for men it takes 30 or more pack-years for the risk to reach statistical significance [13]. Previous studies revealed a gender difference in the effect of smoking on bladder cancer risk; however, one recent study following approximately 500,000 participants reported that smokers, regardless of gender, were at a $50 \%$ higher risk for developing bladder cancer compared with never smokers [14]. Women have additional risk for gender-specific cancers. In a sample of nearly 80,000 postmenopausal women, Luo et al. [15•] observed a $9 \%$ and $16 \%$ increased risk of breast cancer among former smokers and current smokers, respectively, compared with never smokers. Although current smoking was not significantly associated with acquiring human papillomavirus (HPV), it was associated with an increased risk of high-grade cervical intraepithelial neoplasia (CIN), suggesting that smoking may increase the risk of progression from HPV to CIN [16].

\section{Smoking and Cardiovascular Health}

Although smoking increases the risk of coronary heart disease for both genders, several studies have noted gender differences in the association between smoking and cardiovascular health: women who smoke have a $25 \%$ greater increased risk of coronary heart disease than their male-smoker counterparts [17]. The factors contributing to the gender difference in the risk of negative cardiovascular health outcomes in smokers remain unknown, but sex hormones may have a function. Cupisti et al. [18] observed that smoking was associated with increased levels of fasting insulin, free testosterone, and free androgen index for a sample of 346 women with polycystic ovary syndrome. These increased levels resulted in aggravated insulin resistance and, potentially, increased risk of cardiovascular disease [18]. A second contributing factor may be the differential gender effect of smoking on arginine vasopressin (AVP), which has a direct effect on the cardiovascular system. In one small study, it was observed that among non-smokers, men had higher AVP than women, whereas among smokers, women had higher AVP than men [19]. A third contributing factor may be the effect of smoking on arterial hypertension and endothelial dysfunction: compared with their nonsmoking peers, hypertensive female smokers had lower fasting glucose levels, higher diastolic and systolic blood pressure, higher heart rate, and higher intima-media complex in the right carotid artery [20]. Although smoking cessation can significantly reduce this risk, post-cessation weight gains limit the benefits of cessation. Smokers who gained as little as five kilograms (e.g. 11 pounds) during smoking cessation did not have a significant reduction in risk of coronary heart disease compared with current smokers [21••]. Therefore, exercise during smoking cessation may be especially useful for cardiovascular health because it would not only reduce post-cessation weight gain, but has also been shown to improve inflammation (e.g. white blood cells, prothrombotic factor), cholesterol profiles, and cardiovascular fitness (e.g. maximum oxygen consumption) during cessation [22•].

\section{Smoking and sex Hormones}

The effect of smoking on sex hormones has been a topic of increasing interest, given smoking's mediating effect on sex hormones and the subsequent risk of chronic disease, including both cancer and cardiovascular health problems [23, 24]. The effect of smoking on sex hormones seems to vary by menopausal status. Six new studies examining the relationship between smoking and sex hormone levels have been conducted on premenopausal women. Although one study observed no significant differences in sex hormones by smoking status [25], the remaining five studies noted significant differences. Smokers had higher progesterone [26•], higher testosterone 
$[18,26 \bullet]$, and lower absolute levels and less menstrual phase variation of estrogen $[26 \bullet, 27]$. Furthermore, among women and infertile couples undergoing in-vitro fertilization, female smokers had significantly lower antimullerian hormone levels and antral follicle counts, and worse overall in-vitro fertilization outcomes $[28,29]$.

Two studies have examined the association of smoking and sex hormones for peri-menopausal women. Although both studies observed lower antimullerian hormone levels in smokers, the differences reached statistical significance in only one of the studies [30, 31]. Waylen et al. [31] also observed significantly lower inhibin-B values in never smokers compared with current smokers. Consequently, like Freour et al., they concluded that the risk of premature ovarian failure (e.g. early onset menopause) may be related to smoking $[28,29]$.

Two studies of sex hormones and smoking have also been conducted on postmenopausal women. One study observed significantly higher testosterone, androstenedione, estrone, and 17-hydroxy-progesterone in postmenopausal smokers compared with never smokers [32]. The authors also identified an interaction between smoking status and weight: sexhormone-binding globulin was significantly higher in lean female smokers only, whereas estradiol was significantly higher in overweight female smokers only. A second study of postmenopausal women on estrogen therapy examined the difference in estrogen kinetics by smoking status. This study observed significantly lower estrone and estradiol concentrations in smokers compared with nonsmokers after administration of exogenous estrogen [33].

Overall, these data indicate that, compared with their nonsmoking peers, female smokers may have higher progesterone and lower antimullerian hormone levels. Levels of estradiol seemed to vary on the basis of smoking status, menopausal status, and weight, such that significantly lower levels were observed in premenopausal smokers, whereas overweight postmenopausal smokers had significantly higher levels compared with non-smokers. Fortunately, sex hormones may return to levels observed for never smokers soon after cessation: studies did not observe differences between former and never smokers as little as one year post smoking cessation [27, 32].

\section{Smoking and Other Adverse Health Outcomes}

Recent research has also indicated that current smoking is associated with a variety of other adverse health conditions. The effect of smoking on asthma has recently been shown to be moderated by weight and gender. Specifically, women who smoke have higher rates of asthma regardless of weight, whereas for men higher rates of asthma are observed only in normal-weight or under-weight smokers [34].
Women smokers may also have higher rates of incontinence compared with non-smokers; urgency and frequency, but not nocturia or stress incontinence, were observed to be approximately three times more common in current smokers than never smokers [35]. The mechanisms behind this observation remain unknown, but we investigated two possible causes - increased respiratory symptoms and tobacco exposure - within a small cross-sectional sample of smokers. We observed that female smokers, overall, had significantly greater symptoms of incontinence compared with male smokers. Furthermore, regardless of gender, those with self-reported symptoms of incontinence had significantly greater levels of urinary cotinine, a greater number of pack-years of smoking, and a worse self-reported cough [36]. Additional research is needed investigate the relationship between smoking and incontinence prospectively, and to examine whether smoking cessation improves incontinence symptoms.

\section{Factors That Affect Smoking Cessation}

In 2011, more than half of smokers had made a quit attempt in the past year but less than $6 \%$ successfully achieved abstinence [8]. Smoking cessation rates vary by gender and by type of intervention. In general, men may be more likely to respond to nicotine replacement therapy (e.g. transdermal nicotine patch or nicotine gum) whereas women may benefit more from non-nicotine medications or behavioral interventions [37]. Despite these differences, there are currently no gender-specific smoking cessation clinical guidelines available $[37,38]$. As detailed below, factors that affect smoking cessation and vary by gender include fear of weight gain, sex hormones, and mood and personality, among others.

\section{Weight Gain}

Women are particularly sensitive to weight gain at all stages of smoking [37]. Compared with their non-obese peers, obese young women have a two times higher probability of developing a severe nicotine addiction [39•]. Among women who are attempting to quit smoking, those who are dieting may experience greater withdrawal symptoms than those who are not dieting [40]. Women gain more weight than men during attempted smoking cessation, and those of greater age (e.g. 56-64 years old) gain more weight than younger individuals [41]. Significant weight gain occurs for women during attempted cessation regardless of outcomes, with those who are successful typically gaining more weight $[22 \bullet, 42]$. Weight gain during cessation is related to significant increases in both fat and muscle mass [42]. The average weight gain six months post-cessation was ten pounds for a sample of female prisoners, who arguably have a stable energy intake and output 
[43]. These data are particularly concerning given that women smokers who gained more than ten pounds during cessation obtained markedly reduced cardiovascular benefits from quitting smoking [21••]. Therefore, smoking cessation interventions that also limit weight gain are urgently needed, particularly for older women.

Interventions to address cessation-related weight gain may focus on energy intake, energy expenditure, or use of pharmacotherapy. First, regarding energy intake, Kimokoti et al. concluded that those with poor diet quality experienced greater weight gain during smoking cessation than those with a more healthy diet [44]. A higher quality diet may also be associated with improved smoking cessation outcomes: those who self-reported higher fruit and vegetable consumption before attempted cessation were more than three times more likely to report smoking abstinence [45].

Second, exercise could address post-cessation weight gain via increasing energy expenditure. In a small pilot study, participants randomized to a yoga treatment, as compared with a wellness time-control treatment, had a more than three times higher probability of being abstinent three months post quit date; however, there were no significant differences at six months [46•]. Two small studies examined the effect of exercise on smoking cessation. Although neither of these trials observed significant differences in smoking cessation, perhaps because of small sample sizes, the study by Williams et al. observed higher cessation in the exercise group versus the time-control wellness condition group ( $48.3 \%$ versus $23.3 \%$, respectively) [47] whereas the study by Napolitano et al. observed lower cessation in the exercise group versus the group undergoing an intervention that focused on improving body image (10.0\% versus $18.2 \%$, respectively) [48]. The difference in these observations may be related to the study sample or the "dose" of exercise: Napolitano et al. focused on college students exclusively and provided one 45 -minute exercise class per week, whereas Williams et al. enrolled female smokers in general and instructed them to complete $50 \mathrm{~min}$ brisk walking three times per week. Unfortunately, exercise interventions for smoking cessation have been subject to problems of adherence. In these studies, those assigned to the exercise group attended 55.6-86.4\% of intervention sessions [46•, 47, 48]. Williams et al. observed a significant dose-response relationship between the number of intervention sessions attended and probability of cessation for the exercise group but not the control group, suggesting the lack of a significant difference in cessation by treatment group may be attributable to compliance with treatment rather than the treatment itself [47]. To encourage exercise intervention adherence, the authors of these studies recommend including a run-in period, offering flexible schedules, increasing monetary incentives, and/or offering group challenges.

A third potential method of limiting weight gain during smoking cessation is pharmacotherapy. Among participants randomized to naltrexone (versus placebo) for smoking cessation, men were more likely to achieve smoking cessation than women, whereas women gained significantly less weight during smoking cessation than men [49•]. Although the nicotine patch, compared with placebo patch, may increase calorie intake during cessation, those who were randomized to extended use of nicotine patch ( 24 weeks) gained significantly less weight than those who used the nicotine patch for eight weeks $[50,51]$. Finally, our recently published pilot study of topiramate for smoking cessation found that topiramate may be useful for cessation and reducing weight gain [52].

Overall, for both men and women, obesity exacerbates smoking-related morbidity and mortality. Given rising rates of obesity, and the strong probability of weight gain during smoking cessation, there is an urgent need to identify successful smoking cessation interventions that limit weight gain. Weight-concerned and overweight or obese smokers are likely to be receptive to weight management programs as an adjunct to smoking cessation interventions: offering a weight management program has been shown to increase attendance and abstinence [53]. Additional research is needed to examine the use of nutritional counseling, exercise, and/or pharmacotherapy to limit weight gain during smoking cessation.

\section{Sex Hormones}

Sex hormones (primarily estradiol and progesterone) have been implicated as a possible mechanism for gender differences in smoking behavior and cessation. Specifically, progesterone may protect against nicotine addiction, whereas estradiol may enhance vulnerability [54]. The luteal phase (high progesterone to estradiol (PE) ratio), compared with the follicular phase (low PE ratio), may be associated with increased levels of withdrawal symptoms, but there are substantial difficulties in interpreting the literature because of lack of consistency in method, constant fluctuations of endogenous hormonal levels, and problems with selection bias [55]. That said, we recently found that higher levels of anger and craving were associated with greater risk of smoking relapse among women randomized to quit smoking in the follicular phase, but not in the luteal phase [56]. Furthermore, in one study exogenous progesterone treatment (increasing the PE ratio) was associated with a reduced urge to smoke for both male and female smokers during short-term abstinence [57].

A series of studies has been published examining the effect of sex hormones on response to nicotine and smoking. First: after overnight abstinence, nicotine was administered intravenously to men and women, resulting in a greater physiological response (e.g. heart rate) to nicotine in males, whereas the subjective ratings (e.g. craving) were greater for females [58]. Furthermore, for females the follicular phase was associated with greater subjective reduction in craving after nicotine 
administration than the luteal phase [58]. These data are similar to our recent observations, of women without depressive symptoms, revealing that the follicular phase, as compared with the luteal phase, was associated with a more pronounced physiological response to nicotine nasal spray during short-term smoking abstinence (e.g. greater diastolic blood pressure and heart rate, and higher maximum concentrations of nicotine) [59]. Similarly, Schiller et al. [60•] observed that lower PE ratios were associated with increased smoking. They further concluded that, compared with other hormonal measures, the PE ratio and change in estradiol and progesterone over time were the best predictors of smoking behavior [60•]. This finding suggests that both hormones, and their changes over time, may affect smoking behavior. Overall, these data suggest that women may be more responsive to nicotine during the follicular phase (low PE ratio). Prior studies have shown that if women are assigned nicotine replacement therapy, relapse is less likely to occur during the follicular than the luteal phase $[61,62]$. On the other hand, women without nicotine replacement experienced greater relapse during the follicular than the luteal phase [63, 64].

We have recently begun investigating the effect of allopregnanolone, a stress-reducing neuroactive steroid metabolized from progesterone, on smoking behavior. Allopregnanolone had numerous associations with smokingrelated symptoms and nicotine response during short-term smoking abstinence. Although several of these associations were favorable (i.e. higher allopregnanolone was associated with lower perceived stress on the day before quitting, and higher levels of pleasantness on the fourth day of smoking abstinence), some were not (i.e. higher allopregnanolone was associated with greater premenstrual symptoms on the day before quitting, and increased subjective report of physical symptoms on the fourth day of smoking abstinence) [65].

Overall, these data concur with previous literature indicating that menstrual phase, and related sex hormones, affect smoking behavior [55]. Additional research is needed to investigate how exogenous hormones (e.g. progesterone), other sex hormones (e.g. testosterone), and/or other variables that vary by menstrual phase (e.g. allopregnanolone) may affect smoking behavior and risk of smoking relapse for men and women.

\section{Negative Mood and Personality}

The extent to which negative affect predicts smoking relapse varies by gender, and is conflicting. For women, depressive mood, anxiety, anger, and perceived stress were all predictive of time to relapse, whereas for men, craving was a unique predictor of relapse [66]. Although Cofta-Woerpel et al. [67] did not include men, their data reveal that women who had an early smoking lapse reported significantly higher negative mood on quit date when faced with a temptation to smoke, compared with those who remained abstinent. Similarly, Perkins et al. [68] found that, compared with men, women are more likely to increase their puff duration in response to a negative mood. Stress and/or negative affect cues, but not smoking cues, resulted in significantly greater increases in craving, stress and arousal for women compared with men [69]. Conversely, continued smoking and inconsistent former smoking were significant predictors of "negative attitudes towards self" for men, but not women [70]. Also, compared with women, men increased their smoking more during negative mood induction in a lab setting, and in response to negative affect in a natural environment $[68,71]$.

Men may be more susceptible to anger-related problems than women. Recent research indicates that men with childhood conduct problems have a slightly higher probability of future cigarette smoking than women [72]. For both genders, those who experienced problematic anger had a higher probability of smoking daily, being nicotine dependent, being a heavy smoker, and having a lifetime history of unsuccessful quit attempts [73•]. The effect of anger and anger reduction on smoking cessation is unknown.

Smoking cessation success predictions provided by personality patterns differ for men and women smokers. Men with compulsive personality were more likely to quit smoking, whereas men with depressive, antisocial, sadistic, negativistic, masochistic, schizotypal, borderline, and/or impulsivity personalities were less likely to quit smoking. Among women, those with schizoid and/or sociability personality were less likely to quit smoking $[74,75]$. For women in late mid-life, nicotine dependence was predicted by maladaptive personality attributes (for example depression or anxiety), marital or partner conflict, and financial difficulties [76].

Possible new interventions to address the effect of mood on cessation include exercise and pharmacotherapy. During cessation, a yoga intervention (versus a time-control treatment) resulted in significant improvements in mood, perceived health, and overall well-being [46•]. Although yoga and other forms of exercise have not been evaluated as a smoking cessation intervention for those with depression or other mental illness, available research suggests this may be well received: qualitative interviews with women indicated that most were receptive to using exercise with smoking cessation [77]. Regarding pharmacotherapy, Cinciripini et al. [78] compared three randomized treatments for smoking cessation (varenicline, bupropion SR, or placebo) and observed that, although both active treatments were associated with increased cessation rates, only those assigned to varenicline had suppression of depression and reduced smoking reward. Overall, mental health and personality attributes affect smoking and smoking cessation, and these relationships vary by gender. Although research on yoga and/or exercise and on varenicline seems promising, additional research is needed to identify the gender-specific needs of smokers. 


\section{Other Aspects}

Finally, studies have been conducted to address other factors that may minimize the effort of smoking cessation for women. First, we recently compared the combination of very low nicotine content (VLNC) cigarettes paired with the nicotine patch versus either treatment alone (VLNC only or patch only). Women randomized to VLNC alone were more likely to quit smoking than women randomized to patch alone, whereas men randomized to patch alone were more likely to quit smoking than men randomized to VLNC alone [79]. These data support the idea that women tend to smoke more for the non-nicotine factors (e.g. smoking cues, sensation of smoke), whereas men smoke to maintain nicotine levels [37]. Next, Cropsey et al. [80] found that, within a sample of female prisoners, reducing the number of cigarettes smoked per day before a quit attempt may help with preparation for quitting or serve as a marker of motivation to quit smoking, but does not assist with cessation: reduction was unrelated to long-term quit rates. Third, Wetter et al. [81] examined the use of a relapse prevention program for women, delivered via palm pilot, and observed no difference in relapse between the intervention and control groups. Finally, in a study by Weiss et al. [82], young women exposed to aged images of themselves reported increased motivation to quit smoking. More research is needed to identify novel interventions that address gender-specific smoking cessation needs.

\section{Conclusions}

The literature on the effect of smoking-related morbidity and mortality continues to accumulate. For unknown reasons, some of these associations vary by gender such that women are at greater risk, but some do not. Recently the rate of decline in the prevalence of smoking has slowed, indicating the urgent need to identify new and innovative smoking interventions. Smoking has a bidirectional relationship with several factors (e.g. mood and sex hormones); these relationships vary by gender and, ultimately, may limit the ability of an individual to achieve smoking cessation. To address the gender-related needs of smokers, future interventions could use self-care (e.g. exercise or nutrition) and financial assistance (e.g. free child care to attend support groups) as new adjuncts to smoking cessation interventions, and investigate alternative tobacco products and/or novel pharmacotherapy (e.g. very low nicotine content cigarettes or topiramate). Although this review did not examine the effects of ecigarettes, menthol cigarettes, and other tobacco products (e.g. hookah and bidis), additional research is need to examine the effect these products have on adverse health and smoking cessation outcomes.
Acknowledgments This project was supported by NIH/NIDA/OWHR P50-DA033942, NIH/NIDA R01-DA024872, and NIH/NIDA R01DA008075.

\section{Compliance with Ethics Guidelines}

Conflict of Interest Alicia M. Allen, Cheryl Oncken, and Dorothy Hatsukami declare that they have no conflict of interest.

Human and Animal Rights and Informed Consent This article does not contain any studies with human or animal subjects performed by any of the authors.

\section{References}

Papers of particular interest, published recently, have been highlighted as:

- Of importance

-. Of major importance

1. CDC. Smoking and tobacco use. Surgeon General's Reports 2001. Available at: http://www.cdc.gov/tobacco/data_statistics/sgr/2001/ index.htm. Accessed October 10, 2013.

2. CDC. Smoking and tobacco use. Surgeon General's Reports 2004. Available at: http://www.cdc.gov/tobacco/data_statistics/sgr/2004/ index.htm. Accessed October 10, 2013.

3. CDC. Smoking and tobacco use. 2010 Surgeon General's Report: How tobacco smoke causes disease: the biology and behavioral basis for smoking-attributable disease. Available at: http://www. cdc.gov/tobacco/data_statistics/sgr/2010/index.htm. Accessed October 10, 2013.

4. Pirie K, Peto R, Reeves GK, Green J, Beral V. The 21st century hazards of smoking and benefits of stopping: a prospective study of one million women in the UK. Lancet. 2013;381(9861):133-41. This study provides an updated estimate of the effect of smoking on morbidity and mortality in a sample of over 1.2 million women followed for eight years.

5. Taylor DH, Vasselblad V, Henley SJ, Thun MJ, Sloan FA. Benefits of smoking for longevity. Am J Public Health. 2002;92(6):990-6.

6. Duckworth AL, Chertok IRA. Review of perinatal partner-focused smoking cessation interventions. MCN. Am J Matern Child Nurs. 37(3):174-81

7. Duaso M, Duncan D. Health impact of smoking and smoking cessation strategies: current evidence. Br J Community Nurs. 2012;17(8):356-63.

8. CDC. Current cigarette smoking among adults - United States 2011. MMWR. 2012;61:889-94.

9. CDC. Current tobacco use among middle and high school students United States, 2011. MMWR. 2012;61:581-5.

10. Mehta N, Preston S. Continued increases in the relative risk of death from smoking. Am J Public Health. 2012;102(11):2181-6. This study found that despite decline prevalence of smoking, the relative risk of death for current and former smokers continues to rise.

11. Rostron B. Smoking-attributable mortality by cause in the United States: revising the CDC's data and estimates. Nicotine Tob Res. 2013;15(1):238-46.

12. Hjellvik V, Selmer R, Gjessing HK, Tverdal A, Vollset SE. Body mass index, smoking, and risk of death between 40 and 70 years of age in a Norwegian cohort of 32,727 women and 33,475 men. Eur J Epidemiol. 2013;28(1):35-43. 
13. Anderson JC, Moezardalan K, Messina CR, Latreille M, Shaw RD. Smoking and the association of advanced colorectal neoplasia in an asymptomatic average risk population: analysis of exposure and anatomical location in men and women. Dig Dis Sci. 2011;56(12): 3616-23.

14. Freedman ND, Silverman DT, Hollenbeck AR, Schatzkin A, Abnet CC. Association between smoking and risk of bladder cancer among men and women. JAMA. 2011;306(7):737-45.

15. Luo J, Margolis KL, Wactawski-Wende J, Horn K, Messina C, Stefanick ML, et al. Association of active and passive smoking with risk of breast cancer among postmenopausal women: A prospective cohort study. Br Med J. 2013;1016(March 2011):1-25. This paper identified increased risk of breast cancer among women who have smoked more or for a longer period of time.

16. Collins S, Rollason TP, Young LS, Woodman CBJ. Cigarette smoking is an independent risk factor for cervical intraepithelial neoplasia in young women: a longitudinal study. Eur J Cancer. 2010;46(2):405-11.

17. Huxley RR, Woodward M. Cigarette smoking as a risk factor for coronary heart disease in women compared with men: a systematic review and meta-analysis of prospective cohort studies. Lancet. 2011;378(9799):1297-305.

18. Cupisti S, Häberle L, Dittrich R, et al. Smoking is associated with increased free testosterone and fasting insulin levels in women with polycystic ovary syndrome, resulting in aggravated insulin resistance. Fertil Steril. 2010;94(2):673-7.

19. Guaderrama MM, Corwin EJ, Kapelewski CH, Klein LC. Sex differences in effects of cigarette smoking and 24-hr abstinence on plasma arginine vasopressin. Addict Behav. 2011;36(11):11069.

20. Mieczkowska J, Mosiewicz J, Sak J, et al. Effects of cigarette smoking, metabolic syndrome and dehydroepiandrosterone deficiency on intima-media thickness and endothelial function in hypertensive postmenopausal women. Med Sci Monit. 2012;18(4): CR225-34.

21.• Luo J, Rossouw J, Margolis KL. Smoking cessation, weight change, and coronary heart disease among postmenopausal women with and without diabetes. JAMA. 2013;310(1):94-6. This paper is the first to combine the effect of smoking cessation, weight gain and diabetes on coronary heart disease risk.

22. Korhonen T, Goodwin A, Miesmaa P, Dupuis EA, Kinnunen T. Smoking cessation program with exercise improves cardiovascular disease biomarkers in sedentary women. J Women's Health. 2011;20(7):1051-64. This paper is the first to reveal that exercise during smoking cessation results in an improvement of cardiovascular disease biomarkers.

23. Barzi A, Lenz A, Labonte MJ, Lenz HJ. Molecular Pathways: Estrogen Pathway in Colorectal Cancer. Clin Cancer Res. 2013

24. Benson VS, Green J, Pirie K, Beral V. Cigarette smoking and risk of acoustic neuromas and pituitary tumours in the Million Women Study. Br J Cancer. 2010;102(11):1654-6.

25. Dafopoulos A, Dafopoulos K, Georgoulias P, et al. Smoking and AMH levels in women with normal reproductive history. Arch Gynecol Obstet. 2010;282(2):215-9.

26. Dušková M, Simůnková K, Hill M, et al. Chronic cigarette smoking alters circulating sex hormones and neuroactive steroids in premenopausal women. Physiol Res. 2012;61(1):97-111. This is the first study to examine the effect of smoking on sex hormones by menstrual phase in premenopausal women.

27. Gu F, Caporaso NE, Schairer C, et al. Urinary concentrations of estrogens and estrogen metabolites and smoking in caucasian women. Cancer Epidemiol Biomarkers Prev. 2013;22(1):58-68.

28. Fréour T, Dessolle L, Lammers J, Lattes S, Barrière P. Comparison of embryo morphokinetics after in vitro fertilizationintracytoplasmic sperm injection in smoking and nonsmoking women. Fertil Steril. 2013;99(7):1944-50.
29. Freour T, Masson D, Dessolle L, et al. Ovarian reserve and in vitro fertilization cycles outcome according to women smoking status and stimulation regimen. Arch Gynecol Obstet. 2012;285(4):117782.

30. Plante BJ, Cooper GS, Baird DD, Steiner AZ. The impact of smoking on antimullerian hormone levels in women aged 38-50. Menopause. 2010;17(3):571-6.

31. Waylen AL, Jones GL, Ledger WL. Effect of cigarette smoking upon reproductive hormones in women of reproductive age: a retrospective analysis. Reprod Biomed Online. 2010;20(6):861-5.

32. Brand JS, Chan M-F, Dowsett M, et al. Cigarette smoking and endogenous sex hormones in postmenopausal women. J Clin Endocrinol Metab. 2011;96(10):3184-92.

33. Bjarnason NH, Jorgensen HL, Christiansen C. Acute and long-term estradiol kinetics in smoking postmenopausal women. Climacteric. 2012;15:449-54.

34. Chen Y, Mai X-M. Smoking and asthma in men and women with normal weight, overweight, and obesity. J Asthma. 2011;48(5): 490-4.

35. Tähtinen RM, Auvinen A, Cartwright R, Johnson TM, Tammela TLJ, Tikkinen KAO. Smoking and bladder symptoms in women. Obstet Gynecol. 2011;118(3):643-8.

36. Overson E, Allen A, Hertsgaard L, Allen S, Wyman J, Hatsukami D. Severity of incontinence symptoms in smokers and role of tobacco exposure and respiratory symptoms. Available at: http:// www.wmhealth.umn.edu/events/research-conference/conferenceposter-abstracts/index.htm.

37. Perkins KA. Smoking cessation in women: special considerations. CNS Drugs. 2001;15(5):391-411.

38. Torchalla I, Okoli CTC, Bottorff JL, Qu A, Poole N, Greaves L. Smoking cessation programs targeted to women: a systematic review. Women Health. 2012;52(1):32-54.

39. Hussaini AE, Nicholson LM, Shera D, Stettler N, Kinsman S. Adolescent obesity as a risk factor for high-level nicotine addiction in young women. J Adolesc Health. 2011;49(5):511-7. This is the first paper to identify obesity as a risk factor severe nicotine addiction in adolescents.

40. Jenks RA, Higgs S. Reactivity to smoking- and food-related cues in currently dieting and non-dieting young women smokers. J Psychopharmacol. 2011;25(4):520-9.

41. Kasteridis P, Yen ST. Smoking cessation and body weight: evidence from the Behavioral Risk Factor Surveillance Survey. Health Serv Res. 2012;47(4):1580-602.

42. Kleppinger A, Litt MD, Kenny AM, Oncken CA. Effects of smoking cessation on body composition in postmenopausal women. J Women's Health. 2010;19(9):1651-7.

43. Cropsey KL, McClure LA, Jackson DO, Villalobos GC, Weaver MF, Stitzer ML. The impact of quitting smoking on weight among women prisoners participating in a smoking cessation intervention. Am J Public Health. 2010;100(8):1442-8.

44. Kimokoti RW, Newby PK, Gona P, et al. Diet quality, physical activity, smoking status, and weight fluctuation are associated with weight change in women and men. J Nutr. 2010;140:1287-93.

45. Haibach JP, Homish GG, Giovino GA. A longitudinal evaluation of fruit and vegetable consumption and cigarette smoking. Nicotine Tob Res. 2013;15(2):355-63.

46. Bock BC, Fava JL, Gaskins R, et al. Yoga as a complementary treatment for smoking cessation in women. J Women's Health. 2012;21(2):240-8. This pilot study is the first to reveal that yoga may assist with both smoking cessation and improving mood during cessation.

47. Williams DM, Whiteley JA, Dunsiger S, et al. Moderate intensity exercise as an adjunct to standard smoking cessation treatment for women: a pilot study. Psychol Addict Behav. 2010;24(2):349-54.

48. Napolitano MA, Lloyd-Richardson EE, Fava JL, Marcus BH. Targeting body image schema for smoking cessation among college 
females: rationale, program description, and pilot study results. Behav Modif. 2011;35(4):323-46.

49. King AC, Cao D, O'Malley SS, et al. Effects of naltrexone on smoking cessation outcomes and weight gain in nicotinedependent men and women. J Clin Psychopharmacol. 2012;32(5): 630-6. This study observed a significant sex difference in the effect of naltrexone on smoking cessation and weight gain.

50. Allen AM, Kleppinger A, Lando H, Oncken C. Effect of nicotine patch on energy intake and weight gain in postmenopausal women during smoking cessation. Eat Behav. 2013;14(4):420-3.

51. Schnoll RA, Wileyto EP, Lerman C. Extended duration therapy with transdermal nicotine may attenuate weight gain following smoking cessation. Addict Behav. 2012;37(4):565-8.

52. Oncken C, Arias AJ, Feinn R, et al. Topiramate for Smoking Cessation: A Randomized, Placebo-Controlled, Pilot Study. Nicotine Tob Res. 2013

53. Love SJ, Sheffer CE, Bursac Z, Prewitt TE, Krukowski RA, West DS. Offer of a weight management program to overweight and obese weight-concerned smokers improves tobacco dependence treatment outcomes. Am J Addict. 2011;20(1):1-8.

54. Lynch WJ, Sofuoglu M. Role of progesterone in nicotine addiction: evidence from initiation to relapse. Exp Clin Psychopharmacol. 2010;18(6):451-61.

55. Carpenter MJ, Upadhyaya HP, LaRowe SD, Saladin ME, Brady KT. Menstrual cycle phase effects on nicotine withdrawal and cigarette craving: a review. Nicotine Tob Res. 2006;8(5):627-38.

56. Allen AM, Allen SS, Lunos S, Pomerleau CS. Severity of withdrawal symptomatology in follicular versus luteal quitters: The combined effects of menstrual phase and withdrawal on smoking cessation outcome. Addict Behav. 2010;35(6):549-52.

57. Sofuoglu M, Mouratidis M, Mooney M. Progesterone improves cognitive performance and attenuates smoking urges in abstinent smokers. Psychoneuroendocrinology. 2011;36(1):123-32.

58. DeVito E, Herman A, Sofuoglu M. Influences of sex and menstrual cycle phase on response to intravenous nicotine. 2013. Available at: http:/www.cpdd.vcu.edu/Pages/Meetings/PastMeet.html.

59. Allen SS, Allen AM, Kotlyar M, Lunos S, Al'absi M, Hatsukami D. Menstrual phase and depressive symptoms differences in physiological response to nicotine following acute smoking abstinence. Nicotine Tob Res. 2013;15(6):1091-8.

60. Schiller CE, Saladin ME, Gray KM, Hartwell KJ, Carpenter MJ. Association between ovarian hormones and smoking behavior in women. Exp Clin Psychopharmacol. 2012;20(4):251-7. This study examined several different sex hormone variables and concluded that the best predictors of smoking behavior were the progesterone to estradiol ratio, and the change in estradiol and progesterone over time.

61. Franklin TR, Ehrman R, Lynch KG, et al. Menstrual cycle phase at quit date predicts smoking status in an NRT treatment trial: a retrospective analysis. J Womens Health (Larchmt). 2008;17(2): 287-92.

62. Carpenter MJ, Saladin ME, Leinbach AS, Larowe SD, Upadhyaya HP. Menstrual phase effects on smoking cessation: a pilot feasibility study. J Womens Health (Larchmt). 2008;17(2):293-301.

63. Allen SS, Bade T, Center B, Finstad D, Hatsukami D. Menstrual phase effects on smoking relapse. Addiction. 2008;103(5):809-21.

64. Mazure CM, Toll B, McKee SA, Wu R, O'Malley SS. Menstrual cycle phase at quit date and smoking abstinence at 6 weeks in an open label trial of bupropion. Drug Alcohol Depend. 2011;114(1): 68-72.

65. Allen AM. Allopregnanolone during short-term smoking abstinence: Associations with depressive symptoms, smoking-related symptomatology and nicotine response. 2012. Available at: http:// conservancy.umn.edu/bitstream/141131/1/Allen umn 0130E 13289.pdf.
66. Nakajima M, al'Absi M. Predictors of risk for smoking relapse in men and women: a prospective examination. Psychol Addict Behav. 2012;26(3):633-7.

67. Cofta-Woerpel L, McClure JB, Li Y, Urbauer D, Cinciripini PM, Wetter DW. Early cessation success or failure among women attempting to quit smoking: trajectories and volatility of urge and negative mood during the first postcessation week. J Abnorm Psychol. 2011;120(3):596-606.

68. Perkins KA, Giedgowd GE, Karelitz JL, Conklin CA, Lerman C. Smoking in response to negative mood in men versus women as a function of distress tolerance. Nicotine Tob Res. 2012;14(12):1418-25.

69. Saladin ME, Gray KM, Carpenter MJ, LaRowe SD, DeSantis SM, Upadhyaya HP. Gender differences in craving and cue reactivity to smoking and negative affect/stress cues. Am J Addict. 2012;21(3): 210-20.

70. Korhonen T, Koivumaa-Honkanen H, Varjonen J, Broms U, Koskenvuo M, Kaprio J. Cigarette smoking and dimensions of depressive symptoms: longitudinal analysis among Finnish male and female twins. Nicotine Tob Res. 2011;13(4):261-72.

71. Shiffman S, Rathbun SL. Point process analyses of variations in smoking rate by setting, mood, gender, and dependence. Psychol Addict Behav. 2011;25(3):501-10.

72. Von Stumm S, Deary IJ, Kivimäki M, Jokela M, Clark H, Batty GD. Childhood behavior problems and health at midlife: 35-year follow-up of a Scottish birth cohort. J Child Psychol Psychiatry. 2011;52(9):992-1001.

73. Cougle JR, Zvolensky MJ, Hawkins KA. Delineating a relationship between problematic anger and cigarette smoking: a populationbased study. Nicotine Tob Res. 2013;15(1):297-301. This paper is the first population-based study that examined the relationship between problematic anger and smoking.

74. Piñeiro B, López-Durán A, Fernández Del Río E, Martínez U, Becoña E. Gender differences in personality patterns and smoking status after a smoking cessation treatment. BMC Public Health. 2013;13:306.

75. Nieva $G$, Valero $S$, Bruguera E, et al. The alternative five-factor model of personality, nicotine dependence and relapse after treatment for smoking cessation. Addict Behav. 2011;36(10):965-71.

76. Brook JS, Zhang C, Brook DW, Koppel J, Whiteman M. Psychosocial predictors of nicotine dependence among women during their mid-sixties. Am J Addict. 2012;21(4):302-12.

77. Arbour-Nicitopoulos KP, Faulkner GE, Cohn TA, Selby P. Smoking cessation in women with severe mental illness: exploring the role of exercise as an adjunct treatment. Arch Psychiatr Nurs. 2011;25(1):43-52.

78. Cinciripini PM, Robinson JD, Karam-Hage M, et al. Effects of varenicline and bupropion sustained-release use plus intensive smoking cessation counseling on prolonged abstinence from smoking and on depression, negative affect, and other symptoms of nicotine withdrawal. JAMA Psychiatry. 2013;70(5):522-33.

79. Hertsgaard L, Vogel R, Hatsukami D. Gender differences in cigarettes abstinence rates in a study comparing the use of very low nicotine content cigarettes along or in combination with a $21 \mathrm{mg}$ nicotine patch to the use of the patch alone. 2013. Available at: http://srnt.org/conferences/SRNT 2013 Abstracts I-Modified.pdf.

80. Cropsey KL, Jackson DO, Hale GJ, Carpenter MJ, Stitzer ML. Impact of self-initiated pre-quit smoking reduction on cessation rates: results of a clinical trial of smoking cessation among female prisoners. Addict Behav. 2011;36(1-2):73-8.

81. Wetter DW, McClure JB, Cofta-Woerpel L, et al. A randomized clinical trial of a palmtop computer-delivered treatment for smoking relapse prevention among women. Psychol Addict Behav. 2011;25(2):365-71

82. Weiss C, Hanebuth D, Coda P, Dratva J, Heintz M, Stutz EZ. Aging images as a motivational trigger for smoking cessation in young women. Int J Environ Res Public Health. 2010;7(9):3499-512. 